\title{
Prognostic superiority of daytime ambulatory over conventional blood pressure in four populations: a meta-analysis of $\mathbf{7 0 3 0}$ individuals
}

\author{
Tine W. Hansen ${ }^{a, f}$, Masahiro Kikuya ${ }^{b}$, Lutgarde Thijs ${ }^{c}$, \\ Kristina Björklund-Bodegård ${ }^{d}$, Tatiana Kuznetsova ${ }^{c}$, \\ Takayoshi Ohkubo $^{b}$, Tom Richart ${ }^{c}$, Christian Torp-Pedersen ${ }^{f}$, \\ Lars Lind ${ }^{\mathrm{e}}$, Jørgen Jeppesen ${ }^{f}$, Hans Ibsen ${ }^{f}$, Yutaka Imai ${ }^{\mathrm{b}}$ and \\ Jan A. Staessen ${ }^{\mathrm{C}}$, on behalf of the IDACO Investigators
}

\begin{abstract}
Objective To investigate the multivariate-adjusted predictive value of systolic and diastolic blood pressures on conventional (CBP) and daytime (10-20 h) ambulatory (ABP) measurement.
\end{abstract}

Methods We randomly recruited 7030 subjects (mean age 56.2 years; $44.8 \%$ women) from populations in Belgium, Denmark, Japan and Sweden. We constructed the International Database on Ambulatory blood pressure and Cardiovascular Outcomes.

Results During follow-up (median $=9.5$ years), 932 subjects died. Neither CBP nor ABP predicted total mortality, of which $60.9 \%$ was due to noncardiovascular causes. The incidence of fatal combined with nonfatal cardiovascular events amounted to 863 (228 deaths, 326 strokes and 309 cardiac events). In multivariate-adjusted continuous analyses, both CBP and ABP predicted cardiovascular, cerebrovascular, cardiac and coronary events. However, in fully-adjusted models, including both CBP and ABP, CBP lost its predictive value $(P \geq 0.052)$, whereas systolic and diastolic $A B P$ retained their prognostic significance $(P \leq 0.007)$ with the exception of diastolic ABP as predictor of cardiac and coronary events $(P \geq 0.21)$. In adjusted categorical analyses, normotension was the referent group (CBP $<140 / 90 \mathrm{mmHg}$ and $A B P<135 /$ $85 \mathrm{mmHg}$ ). Adjusted hazard ratios for all cardiovascular events were $1.22[95 \%$ confidence interval $(\mathrm{Cl})=0.96-1.53$; $P=0.09]$ for white-coat hypertension $(\geq 140 / 90$ and $<135 / 85 \mathrm{mmHg}) ; 1.62(95 \% \mathrm{Cl}=1.35-1.96 ; P<0.0001)$ for

\section{Introduction}

Current guidelines define normotension and sustained hypertension as a consistently normal or elevated blood pressure on both conventional office and ambulatory measurement $[1,2]$. White-coat hypertension is a raised conventional blood pressure in the presence of a normal daytime blood pressure, whereas masked hypertension is an elevated daytime blood pressure with normal conventional blood pressure [1,2]. Several prospective studies have addressed the cardiovascular risk associated with white-coat [3-12] and masked hypertension [9,11-13]. Most studies involved hypertensive patients [3-7], masked hypertension ( $<140 / 90$ and $\geq 135 / 85 \mathrm{mmHg}$ ); and $1.80(95 \% \mathrm{Cl}=1.59-2.03 ; P<0.0001)$ for sustained hypertension $(\geq 140 / 90$ and $\geq 135 / 85 \mathrm{mmHg}$ ).

Conclusions $A B P$ is superior to $C B P$ in predicting cardiovascular events, but not total and noncardiovascular mortality. Cardiovascular risk gradually increases from normotension over white-coat and masked hypertension to sustained hypertension.J Hypertens 25:1554-1564 @ 2007 Lippincott Williams \& Wilkins.

Journal of Hypertension 2007, 25:1554-1564

Keywords: ambulatory blood pressure, cardiovascular disease, epidemiology, masked hypertension, white-coat hypertension

${ }^{\text {a } R e s e a r c h ~ C e n t e r ~ f o r ~ P r e v e n t i o n ~ a n d ~ H e a l t h, ~ C o p e n h a g e n, ~ D e n m a r k, ~}{ }^{\mathrm{b}}$ Tohoku University Graduate School of Pharmaceutical Sciences and Medicine, Sendai, Japan, ${ }^{\mathrm{C}}$ The Studies Coordinating Centre, Division of Hypertension and

Cardiovascular Rehabilitation, Department of Cardiovascular Diseases, University of Leuven, Leuven, Belgium, ${ }^{\mathrm{d}}$ The Department of Public Health and Caring

Sciences/Geriatrics, Uppsala University, ${ }^{\mathrm{e} T h e}$ Department of Medical Sciences, Uppsala University Hospital, Uppsala, Sweden and ${ }^{\mathrm{f}}$ The Copenhagen University Hospital, Copenhagen, Denmark

Correspondence to Jan A. Staessen, Studies Coordinating Centre, Division of Hypertension and Cardiovascular Rehabilitation, Department of Cardiovascular Diseases, University of Leuven, Campus Gasthuisberg, Herestraat 49, Box 702. B-3000 Leuven, Belgium

Tel: +32 1634 7104; fax: +32 1634 7106; e-mail: jan.staessen@med.kuleuven.be

Received 9 December 2006 Revised 9 March 2007 Accepted 4 April 2007

See editorial commentary on page 1565

including $[3,6]$ or excluding $[4,5,7]$ a normotensive control group. Fewer reports were population-based $[9,11-$ 13] or pooled hypertensive patients with randomly recruited subjects [10]. The interpretation of previous studies on white-coat [3-12] and masked [9,11-13] hypertension is difficult, due to divergent thresholds for ambulatory hypertension, and because, in some studies, most patients were followed up when they were on antihypertensive drug treatment [4,7], and/or because of the relatively low incidence of events $[5,7,8]$, short duration of follow-up [3,5-7] or restriction of follow-up to mortality [12]. 
We constructed an international database of population studies with the goal to investigate the relation between fatal and nonfatal outcomes and the ambulatory and conventional blood pressures based on long-term follow-up and a large number of events, while adjusting for cardiovascular risk factors [14,15]. In the present study, we assessed risk associated with the conventional and ambulatory blood pressures analysed as continuous exposure variables. We also reported estimates of risk associated with white-coat and masked hypertension, relative to normotension and sustained hypertension.

\section{Methods}

\section{Study population}

We constructed the International Database on Ambulatory blood pressure monitoring in relation to Cardiovascular Outcomes (IDACO) [14,15]. Studies were eligible for inclusion, if they involved a random population sample, if information on the conventional and ambulatory blood pressures and cardiovascular risk factors were available at baseline, and if the subsequent follow-up included fatal and nonfatal outcomes. An electronic search of the English literature, using 'ambulatory blood pressure monitoring' and 'population' as search terms identified eleven studies [11-13,16-23]. Seven were excluded because follow-up was still ongoing $[17,19-23]$ or because follow-up did not include nonfatal events [12].

For the current analysis, we considered 2311 residents from Copenhagen, Denmark [11], 2542 subjects recruited from Noorderkempen, Belgium [18], 1535 inhabitants of Ohasama, Japan [16], and 1221 men from the population of Uppsala, Sweden [13]. Thus, on 30 April 2006, the number of subjects available for analysis totalled 7609. All studies included randomly selected population samples and the participation rates were $70.2 \%$ in Copenhagen [11], 70.0\% in Belgium [18], $77.1 \%$ in Ohasama [16] and $72.6 \%$ in Uppsala [13]. All studies contributing to the IDACO database received ethical approval and have been described in detail $[11,13,16,18]$. All participants provided their informed written consent. Of the 7609 subjects, 579 were excluded because their conventional $(n=220)$ or daytime ambulatory blood pressure $(n=79)$ was not measured, because their daytime ambulatory blood pressure was the average of fewer than ten readings $(n=53)$, or because they were younger than 18 years at enrolment $(n=227)$. Thus, the number of subjects included in the present analyses totalled 7030 .

\section{Conventional and ambulatory blood pressure measurement}

Experienced observers measured the conventional blood pressure with a standard mercury sphygmomanometer $[11,13,18]$ or a validated [24] auscultatory device (USM700F; UEDA Electronic Works, Tokyo, Japan) [16], using the appropriate cuff size, after the subjects had rested for at least $2 \mathrm{~min}$ in the sitting $[11,16,18]$ or supine [13] position. The conventional blood pressure was the average of two consecutive readings obtained either at the subjects' homes [18] or at an examination centre $[11,13,16]$.

We programmed portable blood pressure monitors to obtain daytime readings at intervals ranging from $15 \mathrm{~min}$ [11] to $30 \mathrm{~min}$ [16]. The devices implemented an auscultatory algorithm (Accutracker II; Suntech Medical Instruments Inc., Morrisville, North Carolina, USA) [25] in Uppsala [13] or an oscillometric technique (SpaceLabs 90202 and 90207; SpaceLabs Inc., Redmond, Washington, USA) [26,27] in Noorderkempen [18]. The Takeda TM-2421 recorders (A\&D, Tokyo, Japan) [28] and the ABPM-630 devices (Nippon Colin, Komaki, Japan) [29], used in Copenhagen [11] and Ohasama [16], respectively, implemented both techniques, but only the oscillometric readings were analyzed.

To achieve a high degree of standardization, the same SAS macro (SAS software, version 9.1; SAS Institute, Cary, North Carolina, USA) processed all individual recordings, which stayed either unedited $[11,13,18]$ or were only minimally edited [16], according to previously published criteria [30]. We calculated the averaged daytime blood pressure weighted for the time interval between consecutive readings. Accounting for the pattern of the daily activities of the study participants, we defined daytime as the interval ranging from $1000 \mathrm{~h}$ to $2000 \mathrm{~h}$ in Europeans $[11,13,18]$, and from $0800 \mathrm{~h}$ to $1800 \mathrm{~h}$ in Japanese [16]. Pulse pressure was the difference between the systolic and diastolic blood pressure. Mean arterial pressure was diastolic blood pressure plus onethird of pulse pressure.

In line with current guidelines for the diagnosis and management of hypertension [1,2], we defined conventional hypertension as a blood pressure equal to or exceeding $140 \mathrm{mmHg}$ systolic or $90 \mathrm{mmHg}$ diastolic. The corresponding thresholds for ambulatory hypertension were $135 \mathrm{mmHg}$ systolic and $85 \mathrm{mmHg}$ diastolic. In line with suggestions by Verdecchia et al. [31], we also defined ambulatory hypertension, using 130 and $80 \mathrm{mmHg}$ as systolic and diastolic cut-off limits. Patients on antihypertensive drug treatment were classified according to their treated blood pressure. Normotension and sustained hypertension were a consistently normal or elevated blood pressure on both conventional and ambulatory measurement $[1,2]$. White-coat hypertension was a raised conventional blood pressure in the presence of a normal daytime blood pressure $[1,2]$. Masked hypertension was an elevated ambulatory blood pressure with normal conventional blood pressure [1,2].

\section{Other measurements}

In all cohorts, a questionnaire was used to obtain detailed information on each subject's medical history, intake of 
medications, and lifestyle. We defined smoking and drinking as the current use of tobacco and alcohol. Body mass index was body weight in kilograms divided by height in meters squared $\left(\mathrm{kg} / \mathrm{m}^{2}\right)$. Previous cardiovascular disease included cardiac disorders, stroke, transient ischemic attack, and peripheral vascular disease. Total serum cholesterol and blood glucose were determined by automated enzymatic methods on venous blood samples. Diabetes mellitus was a self-reported diagnosis, a fasting or random blood glucose level of at least $7.0 \mathrm{mmol} / \mathrm{l}$ $(126 \mathrm{mg} / \mathrm{dl})$ or $11.1 \mathrm{mmol} / \mathrm{l}(200 \mathrm{mg} / \mathrm{dl})$, respectively, or use of antidiabetic drugs [32].

\section{Ascertainment of events}

We ascertained vital status and the incidence of fatal and nonfatal diseases from the appropriate sources in each country, as previously described in detail $[11,13,33,34]$. Fatal and nonfatal stroke did not include transient ischemic attacks. Coronary events encompassed death from ischemic heart disease, sudden death, nonfatal myocardial infarction, and surgical and transluminal coronary revascularization. Cardiac events comprised coronary endpoints and fatal and nonfatal heart failure. In the Danish [11] and Swedish [13] cohorts, the diagnosis of heart failure required hospitalization. In the Japanese [16,33] and Belgian [18,34] cohorts, heart failure was either a clinical diagnosis or the diagnosis on the death certificate but, in all cases, validated against hospital records or the records held by general practitioners. The composite cardiovascular endpoint included all aforementioned endpoints plus cardiovascular mortality. In all outcome analyses, we only considered the first event within each category.

\section{Statistical analysis}

For database management and statistical analysis, we used SAS software, version 9.1 (SAS Institute). For comparison of means and proportions, we applied the standard normal z-test for large samples and the chi-squared test, respectively. We first plotted the incidence of cardiovascular events according to the cross classification of subjects by conventional and ambulatory blood pressure measurement, using Cox models standardized to the sex distribution and mean age of the whole study population. We ascertained that the proportional hazard assumption underlying Cox regression was fulfilled by testing the interaction between follow-up time and blood pressure categories. Next, we modelled the multivariate-adjusted risk associated with the conventional and ambulatory blood pressures treated both as continuous and as categorical variables. In these Cox regression models, we adjusted for cohort, sex, age, body mass index, serum cholesterol, smoking and drinking, history of cardiovascular disease, diabetes mellitus, and antihypertensive drug treatment. We adjusted for cohort by introducing three design variables in the Cox models. We additionally adjusted the Cox models relating outcome to pulse pressure for mean arterial pressure [35]. For the categorical analyses, we presented hazard ratios as floating absolute risks and calculated their standard errors as described by Easton et al. [36]. This approach allows the calculation of a $95 \%$ confidence interval (CI) for the relative risk in the referent group. We evaluated differences between hazard ratios, using the test statement in the Cox regression procedure, as implemented in the SAS package. $P<0.05$ (two-tailed) was considered statistically significant.

\section{Results}

\section{Baseline characteristics of the participants}

The 7030 subjects included $3148(44.8 \%)$ women and 1520 patients $(21.8 \%)$ on antihypertensive drug treatment. Mean $\pm S D$ values were $56.2 \pm 14$. 4 years for age, $131.8 \pm 19.6 \mathrm{mmHg}$ and $79.4 \pm 11.3 \mathrm{mmHg}$ for systolic and diastolic blood pressure on conventional measurement, and $131.8 \pm 14.9 \mathrm{mmHg}$ and $78.5 \pm 9.1 \mathrm{mmHg}$ for systolic and diastolic blood pressure on daytime monitoring. Of the participants, $3473(49.4 \%)$ had normotension, $743(10.6 \%)$ had white-coat hypertension, 1024 (14.6\%) had masked hypertension, and 1790 (25.4\%) had sustained hypertension. Table 1 shows the baseline characteristics of these four groups. Between-group differences were significant for all variables $(P<0.0001)$. Across cohorts, the prevalence of white-coat hypertension was lowest in Copenhagen and highest in Uppsala (6.7 versus $17.0 \%)$, whereas the opposite was true for the prevalence of masked hypertension (20.1 versus $11.3 \%$ ).

\section{Exploratory analyses}

During follow-up $($ median $=9.5$ years; 5 th to 95 th percentile interval $=2.7-14.0$ years), 64958 person-years accrued. Figure 1 shows the incidence of cardiovascular events in the four blood pressure groups with rates standardized to the sex distribution and mean age of the whole study population. The incidence of cardiovascular events increased from normotension over whitecoat and masked hypertension to sustained hypertension ( $P$ for trend $<0.0001$ ). The number of events and crude incidence rates expressed in percentage are shown in Table 2 for mortality and in Table 3 for fatal and nonfatal cardiovascular events combined. Cardiac events consisted of 147 fatal and 321 nonfatal events, including 47 fatal and 168 nonfatal cases of acute myocardial infarction, 79 sudden deaths, 21 fatal and 127 nonfatal cases of heart failure, and 26 cases of surgical and percutaneous coronary revascularization. Most revascularization procedures occurred in Belgium $(n=20)$ and a few others occurred in Denmark $(n=6)$.

\section{Adjusted continuous analyses}

The multivariate-adjusted hazard ratios (95\% CI) associated with each $10-\mathrm{mmHg}$ increase in systolic blood pressure or pulse pressure or each $5-\mathrm{mmHg}$ increase in diastolic blood pressure are shown in Table 2 for 
Table 1 Baseline characteristics of participants by cross-classification of conventional and daytime blood pressures

\begin{tabular}{|c|c|c|c|c|}
\hline Characteristic & Normotension $(n=3473)$ & White-coat HT $(n=743)$ & Masked HT $(n=1024)$ & Sustained HT $(n=1790)$ \\
\hline \multicolumn{5}{|l|}{ Anthropometrics } \\
\hline Women $(n)$ & $1909(55.0)$ & $300(40.4)$ & $406(39.7)$ & $533(29.8)$ \\
\hline Age (years) & $50.9 \pm 14.7$ & $62.3 \pm 12.0$ & $56.5 \pm 13.0$ & $63.6 \pm 10.6$ \\
\hline Body mass index $\left(\mathrm{kg} / \mathrm{m}^{2}\right)$ & $24.5 \pm 3.7$ & $26.0 \pm 4.4$ & $25.8 \pm 3.9$ & $27.0 \pm 4.1$ \\
\hline \multicolumn{5}{|l|}{ Conventional blood pressure $(\mathrm{mmHg})$} \\
\hline Systolic & $118.9 \pm 10.7$ & $148.0 \pm 12.8$ & $125.6 \pm 9.2$ & $153.8 \pm 15.1$ \\
\hline Diastolic & $73.1 \pm 8.1$ & $85.9 \pm 9.5$ & $77.5 \pm 7.6$ & $90.0 \pm 9.9$ \\
\hline Pulse pressure & $45.7 \pm 9.9$ & $62.2 \pm 15.7$ & $48.1 \pm 10.3$ & $63.7 \pm 15.6$ \\
\hline \multicolumn{5}{|l|}{ Daytime blood pressure $(\mathrm{mmHg})$} \\
\hline Daytime systolic & $121.4 \pm 7.8$ & $126.3 \pm 6.5$ & $141.2 \pm 8.3$ & $148.7 \pm 11.8$ \\
\hline Daytime diastolic & $73.5 \pm 5.9$ & $74.9 \pm 6.0$ & $84.0 \pm 7.3$ & $86.5 \pm 8.7$ \\
\hline Pulse pressure & $48.0 \pm 6.4$ & $51.4 \pm 6.9$ & $57.6 \pm 9.6$ & $62.4 \pm 11.1$ \\
\hline \multicolumn{5}{|l|}{ Risk factors } \\
\hline Antihypertensive treatment $(n)$ & $421(12.1)$ & $290(39.0)$ & $191(18.7)$ & $618(34.5)$ \\
\hline Current smokers $(n)$ & $1093(31.6)$ & $142(19.4)$ & $391(38.4)$ & $507(28.5)$ \\
\hline Current drinkers $(n)$ & 1425 (43.4) & $316(51.2)$ & $622(65.2)$ & $1136(73.9)$ \\
\hline Serum cholesterol $(\mathrm{mmol} / \mathrm{l})$ & $5.47 \pm 1.09$ & $5.86 \pm 1.15$ & $5.80 \pm 1.11$ & $5.96 \pm 1.13$ \\
\hline History of cardiovascular disease $(n)$ & $213(6.1)$ & $97(13.0)$ & $84(8.2)$ & $199(11.1)$ \\
\hline Diabetes mellitus $(n)$ & $157(4.5)$ & $67(9.0)$ & $83(8.1)$ & $184(10.3)$ \\
\hline
\end{tabular}

Data are mean $\pm S D$ or number of subjects (\%). HT, Hypertension (for conventional and ambulatory thresholds, see Methods). All between-group differences were significant $(P \leq 0.0001)$.

mortality and in Table 3 for fatal combined with nonfatal cardiovascular events. We adjusted all analyses for cohort, sex, age, body mass index, serum cholesterol, smoking and drinking, history of cardiovascular disease, diabetes mellitus, and antihypertensive drug treatment. The analyses involving pulse pressure were also adjusted for mean arterial pressure [35]. Fully-adjusted models included blood pressure on conventional as well as daytime ambulatory measurement.

In adjusted and fully-adjusted models, the three blood pressure components on daytime ambulatory measurement, but not on conventional measurement, were significant predictors of cardiovascular mortality, but not of total mortality. Systolic and diastolic blood pressure and pulse pressure on conventional as well as ambulatory measurement did not predict noncardiovascular mortality in adjusted $(P \geq 0.44)$ or fully adjusted $(P \geq 0.49)$ models (Table 2). This explains the weak association of total mortality (55.6\% due to noncardiovascular causes) with the daytime ambulatory blood pressure in adjusted $(0.014 \leq P \leq 0.30)$ and fully-adjusted $(P \geq 0.14)$ models (Table 2).

Figure 2 shows the 10-year absolute risk of cardiovascular events in continuous analyses adjusted for cohort and the aforementioned risk factors. In fully-adjusted models, the daytime blood pressure remained a significant predictor for all cardiovascular events over and beyond the conventional blood pressure (Table 3 and Fig. 2). This was also the case for cause-specific cardiovascular endpoints with the exception of the daytime diastolic blood pressure as predictor of cardiac events (hazard ratio, $1.03 ; P=0.45)$ and coronary heart disease, including or

Fig. 1
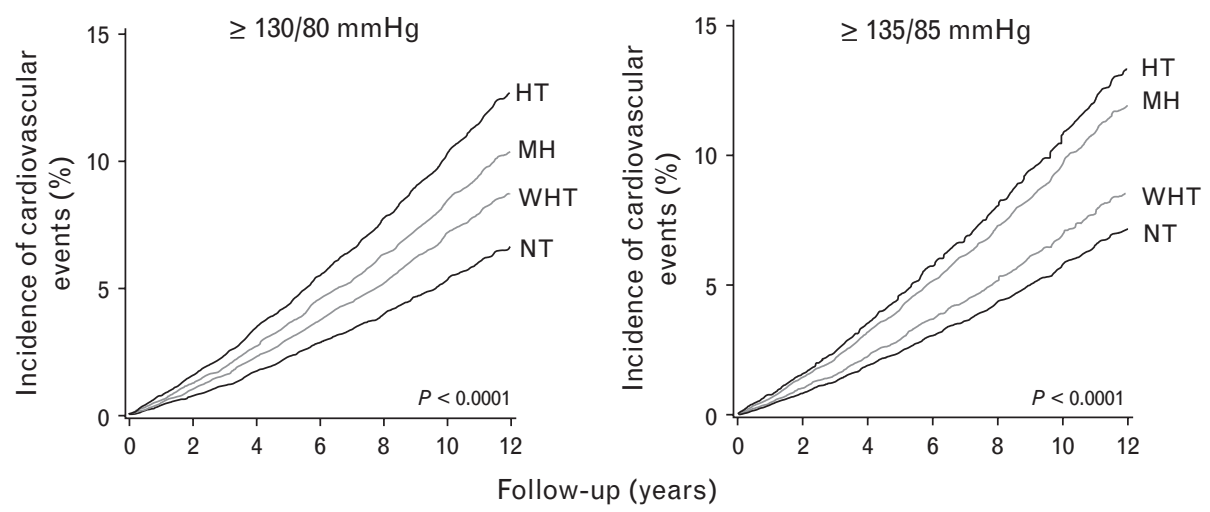

Incidence of cardiovascular events according to the cross classification of subjects by conventional and daytime ambulatory blood pressure. NT, normotension; WHT, white-coat hypertension; MH, masked hypertension; HT, sustained hypertension. The analyses were based on (a) lower $(\geq 130 / 80 \mathrm{mmHg})$ or (b) higher $(\geq 135 / 85 \mathrm{mmHg})$ cut-off limits for daytime ambulatory hypertension. Incidence was standardized to the sex distribution and mean age in the whole study population. The $P$-values are for trend across the blood pressure groups. 
Table 2 Multivariate-adjusted hazard ratios for mortality

\begin{tabular}{|c|c|c|c|c|}
\hline Label & & Total & Noncardiovascular & Cardiovascular \\
\hline Number of deaths, $n(\%)$ & & 932 (13.3) & $524(7.4)$ & $364(5.2)$ \\
\hline \multicolumn{5}{|c|}{ Conventional blood pressure } \\
\hline \multirow[t]{2}{*}{ Systolic } & Adjusted & $1.05(1.00-1.09)^{*}$ & $1.01(0.95-1.07)$ & $1.10(1.03-1.17)$ \\
\hline & Fully adjusted & $1.03(0.98-1.08)$ & $1.02(0.95-1.09)$ & $1.03(0.96-1.11)$ \\
\hline \multirow[t]{2}{*}{ Diastolic } & Adjusted & $1.01(0.98-1.05)$ & $0.99(0.94-1.04)$ & $1.05(0.99-1.11)$ \\
\hline & Fully adjusted & $1.00(0.96-1.05)$ & $1.00(0.95-1.06)$ & $1.00(0.94-1.07)$ \\
\hline \multirow[t]{2}{*}{ Pulse pressure } & Adjusted & $1.05(0.99-1.12)$ & $1.03(0.95-1.12)$ & $1.07(0.98-1.18)$ \\
\hline & Fully adjusted & $1.03(0.97-1.10)$ & $1.03(0.94-1.13)$ & $1.03(0.93-1.13)$ \\
\hline \multicolumn{5}{|l|}{ Daytime blood pressure } \\
\hline \multirow[t]{2}{*}{ Systolic } & Adjusted & $1.07(1.01-1.12)^{*}$ & $0.99(0.92-1.06)$ & $1.18(1.09-1.27)^{\ddagger}$ \\
\hline & Fully adjusted & $1.05(0.99-1.11)$ & $0.99(0.90-1.07)$ & $1.16(1.05-1.27)^{\dagger}$ \\
\hline \multirow[t]{2}{*}{ Diastolic } & Adjusted & $1.02(0.98-1.07)$ & $0.99(0.94-1.04)$ & $1.11(1.04-1.18)^{\dagger}$ \\
\hline & Fully adjusted & $1.02(0.96-1.05)$ & $0.98(0.91-1.05)$ & $1.11(1.03-1.20)^{\dagger}$ \\
\hline \multirow[t]{2}{*}{ Pulse pressure } & Adjusted & $1.08(0.99-1.17)$ & $1.04(0.93-1.17)$ & $1.09(0.96-1.23)$ \\
\hline & Fully adjusted & $1.06(0.97-1.16)$ & $1.02(0.90-1.16)$ & $1.06(0.92-1.21)$ \\
\hline
\end{tabular}

The cause of death was unknown in 44 cases. Hazard ratios (95\% confidence interval) are for the risk associated with 10 -mmHg increases in systolic blood pressure and pulse pressure or $5-\mathrm{mmHg}$ increases in diastolic blood pressure. All hazard ratios were adjusted for cohort, sex, age, body mass index, serum cholesterol, smoking and drinking, history of cardiovascular disease, diabetes mellitus, and antihypertensive drug treatment. Hazard ratios for pulse pressure were additionally adjusted for mean arterial pressure. Models including both conventional as well as daytime blood pressure are labelled as fully adjusted. Significance of the hazard ratios: $*<0.05$, ${ }^{\dagger} P<0.01,{ }^{\ddagger} P<0.0001$.

excluding the 26 incident cases of coronary revascularization (hazard ratios $\leq 1.05 ; P \geq 0.21$ ). By contrast, in fully-adjusted models, the conventional blood pressure was not predictive of fatal combined with nonfatal outcomes, over and beyond the ambulatory daytime blood pressure.

\section{Adjusted categorical analyses}

Figure 3 shows the hazard ratios (95\% CI) for all combined cardiovascular events according to the cross-classification of conventional and daytime ambulatory blood pressure. Cardiovascular risk increased across the hypertensive groups with the highest risk in the patients with sustained hypertension $(P$-value for trend $<0.0001)$. These results were consistent in analyses based on the higher $(\geq 135 / 85 \mathrm{mmHg})$ and lower $(\geq 130 / 80 \mathrm{mmHg})$ [31] cut-off limits for daytime ambulatory hypertension.
Compared to normotension, white-coat hypertensive patients had a slightly increased risk, but none of the hazard ratios reached significance $(0.63 \geq P \geq 0.09$; Fig. 3). Using $135 / 85 \mathrm{mmHg}$ as the cut-off limit, whitecoat hypertensive patients had higher daytime blood pressures than the normotensive reference group. The differences averaged $4.9 \mathrm{mmHg}$ systolic and $1.4 \mathrm{mmHg}$ diastolic (no $P$-values calculated because the classification rested on blood pressure). After additional adjustment for the daytime systolic blood pressure, the hazard ratios associated with white-coat hypertension were 1.16 (95\% CI $=0.91-1.47 ; P=0.23$ ) for all cardiovascular events, 1.03 (95\% CI $=0.72-1.49 ; P=0.87$ ) for stroke, and $1.22(95 \% \mathrm{CI}=0.87-1.69 ; P=0.24)$ for cardiac events. The hazard ratios, relative to normotension, were similar for masked hypertension and sustained hypertension $(P \geq 0.14)$ with the exception of the hazard ratio for

Table 3 Multivariate-adjusted hazard ratios for fatal and nonfatal events combined

\begin{tabular}{|c|c|c|c|c|c|c|}
\hline Label & & All events & Stroke & Cardiac & $\mathrm{CHD}+$ & $\mathrm{CHD}-$ \\
\hline Number of events, $n(\%)$ & & $863(12.3)$ & $397(5.7)$ & $468(6.7)$ & $353(5.0)$ & $333(4.7)$ \\
\hline \multicolumn{7}{|c|}{ Conventional blood pressure } \\
\hline \multirow[t]{2}{*}{ Systolic } & Adjusted & $1.12(1.08-1.17)^{\ddagger}$ & $1.13(1.07-1.20)^{\ddagger}$ & $1.12(1.06-1.19)^{\ddagger}$ & $1.10(1.03-1.18)^{\dagger}$ & $1.11(1.04-1.19)^{\dagger}$ \\
\hline & Fully adjusted & $1.05(1.00-1.10)$ & $1.05(0.98-1.12)$ & $1.06(0.99-1.13)$ & $1.02(0.94-1.11)$ & $1.03(0.95-1.12)$ \\
\hline \multirow[t]{2}{*}{ Diastolic } & Adjusted & $1.07(1.03-1.11)^{\ddagger}$ & $1.09(1.03-1.14)^{\dagger}$ & $1.08(1.02-1.13)^{*}$ & $1.09(1.03-1.15)^{\ddagger}$ & $1.09(1.02-1.16)^{\dagger}$ \\
\hline & Fully adjusted & $1.03(0.99-1.07)$ & $1.02(0.96-1.08)$ & $1.06(0.99-1.13)$ & $1.05(0.98-1.13)$ & $1.06(0.98-1.14)$ \\
\hline \multirow[t]{2}{*}{ Pulse pressure } & Adjusted & $1.08(1.01-1.15)^{*}$ & $1.06(0.97-1.16)^{\dagger}$ & $1.10(1.01-1.19)^{*}$ & $1.01(0.92-1.12)$ & $1.02(0.92-1.13)$ \\
\hline & Fully adjusted & $1.02(0.96-1.09)$ & $1.01(0.92-1.11)$ & $1.02(0.93-1.12)$ & $0.94(0.85-1.05)$ & $0.95(0.85-1.06)$ \\
\hline \multicolumn{7}{|l|}{ Daytime blood pressure } \\
\hline \multirow[t]{2}{*}{ Systolic } & Adjusted & $1.21(1.15-1.27)^{\ddagger}$ & $1.25(1.16-1.34)^{\ddagger}$ & $1.18(1.10-1.26)^{\ddagger}$ & $1.19(1.10-1.29)^{\ddagger}$ & $1.20(1.11-1.30)^{\ddagger}$ \\
\hline & Fully adjusted & $1.17(1.10-1.24)^{\ddagger}$ & $1.21(1.12-1.32)^{\ddagger}$ & $1.13(1.04-1.23)^{\ddagger}$ & $1.17(1.07-1.29)^{\ddagger}$ & $1.18(1.07-1.30)^{\dagger}$ \\
\hline \multirow[t]{2}{*}{ Diastolic } & Adjusted & $1.11(1.07-1.15)^{\ddagger}$ & $1.17(1.10-1.23)^{\ddagger}$ & $1.07(1.01-1.13)^{*}$ & $1.09(1.03-1.17)^{\dagger}$ & $1.09(1.02-1.17)^{*}$ \\
\hline & Fully adjusted & $1.09(1.04-1.14)^{\ddagger}$ & $1.15(1.08-1.23)^{\ddagger}$ & $1.03(0.96-1.10)$ & $1.06(0.98-1.15)$ & $1.05(0.96-1.15)$ \\
\hline \multirow[t]{2}{*}{ Pulse pressure } & Adjusted & $1.14(1.05-1.23)^{\dagger}$ & $1.06(0.94-1.20)$ & $1.22(1.10-1.35)^{\ddagger}$ & $1.16(1.02-1.31)^{*}$ & $1.17(1.03-1.33)^{*}$ \\
\hline & Fully adjusted & $1.11(1.02-1.21)^{*}$ & $1.03(0.90-1.33)$ & $1.19(1.06-1.33)^{\dagger}$ & $1.17(1.02-1.33)^{*}$ & $1.18(1.03-1.35)^{*}$ \\
\hline
\end{tabular}

$\mathrm{CHD}+/ \mathrm{CHD}$ - indicate coronary heart disease including/excluding coronary bypass surgery and percutaneous transluminal coronary angioplasty. Hazard ratios (95\% confidence interval) are for the risk associated with 10- $\mathrm{mmHg}$ increases in systolic blood pressure and pulse pressure or 5 -mmHg increase in diastolic blood pressure. All hazard ratios were adjusted for cohort, sex, age, body mass index, serum cholesterol, smoking and drinking, history of cardiovascular disease, diabetes mellitus, and antihypertensive drug treatment. Hazard ratios for pulse pressure were additionally adjusted for mean arterial pressure. Models including both conventional as well as daytime blood pressure are labelled as fully adjusted. Significance of the hazard ratios: ${ }^{*} P<0.05,{ }^{\dagger} P<0.01,{ }^{\ddagger} P<0.0001$. 

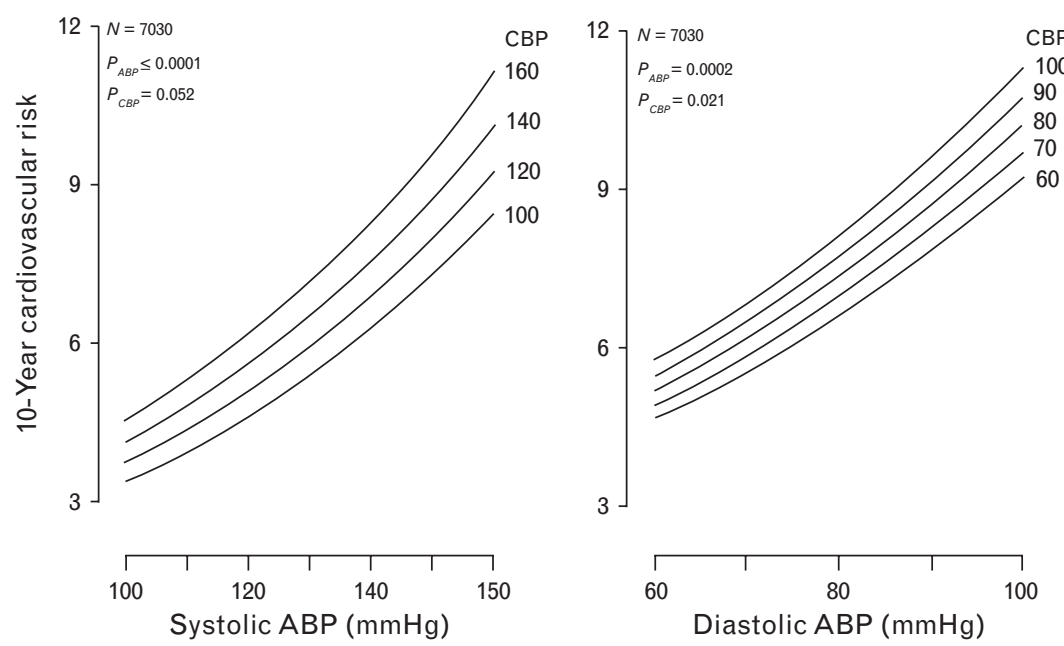

Absolute 10-year risk of a cardiovascular event in relation to the conventional and daytime ambulatory blood pressure. ABP, Ambulatory daytime blood pressure; CBP, conventional blood pressure. Risk estimates are for (a) systolic blood pressure and (b) diastolic blood pressure and were adjusted for cohort, sex, age, body mass index, serum cholesterol, smoking and drinking, history of cardiovascular disease, diabetes mellitus, and antihypertensive drug treatment. $P$-values are for the independent contributions of ABP and CBP to risk.

all cardiovascular events based on the lower definition $(\geq 130 / 80 \mathrm{mmHg})$ of ambulatory hypertension $(1.44$ versus $1.77 ; P=0.036$; Fig. 3 ).

With all fatal and nonfatal cardiovascular events as outcome, we performed sensitivity analyses (Table 4), which we adjusted as before and which were based on the higher cut-off limit for ambulatory hypertension $(\geq 135 / 85 \mathrm{mmHg})$. The results in women and men, at younger ( $<60$ years) and older ( $\geq 60$ years) age, and in subjects taking or not taking antihypertensive drugs at baseline, were consistent $(P$-values for interaction $\geq 0.18)$ and confirmed the observations in all subjects (Table 3 and Fig. 2). Moreover, analyses from which we excluded subjects with previous cardiovascular disease or from which we excluded one cohort at a time were also confirmatory (Table 4). Thus, previous cardiovascular disease or one particular cohort did not drive our main results. Similarly, when we excluded incident cases of surgical and percutaneous coronary revascularization, our conclusions also remained unchanged (Table 4).

By censoring the adjusted Cox models for all cardiovascular events at 6, 9 and 12 years [10], we furthermore explored whether the risk of white-coat hypertension, compared to normotension, changed with longer followup. For the higher threshold of ambulatory hypertension $(\geq 135 / 85 \mathrm{mmHg})$, the hazard ratios were $1.08(95 \%$ $\mathrm{CI}=0.61-1.88 ; \quad P=0.79), \quad 1.20 \quad(95 \% \quad \mathrm{CI}=0.86-1.69$; $P=0.29)$ and $1.30(95 \% \mathrm{CI}=1.01-1.68 ; P=0.043)$, when censoring at 6,9 and 12 years. The corresponding hazard ratios for white-coat hypertension compared to sustained hypertension were $0.64(95 \% \mathrm{CI}=0.37-1.12 ; P=0.11)$, $0.65(95 \% \mathrm{CI}=0.46-0.91 ; P=0.013)$ and $0.73(95 \%$ $\mathrm{CI}=0.57-0.94 ; P=0.014)$, respectively. For the entire follow-up period (without censoring), the hazard ratio for white-coat hypertension compared to sustained hypertension was $0.68(95 \% \mathrm{CI}=0.52-0.87 ; P=0.003)$.

\section{Discussion}

Our current meta-analysis of individual subject data included over 7000 people randomly recruited from four populations and covered approximately 10 years of follow-up with more than 800 new cardiovascular endpoints. The key finding was that ambulatory blood pressure monitoring was by far superior to conventional blood pressure measurement in the prediction of cardiovascular events and risk stratification. These results rested primarily on continuous analyses unbiased by the application of arbitrary blood pressure thresholds. Furthermore, categorical analyses confirmed the superiority of ambulatory monitoring over conventional blood pressure and demonstrated that the risks conferred by white-coat hypertension and masked hypertension were intermediate to those associated with normotension and sustained hypertension. Finally, we noticed that, over a prolonged period of follow-up, the risk of white-coat hypertension remained significantly less than that of sustained hypertension.

In 1983, Perloff et al. [37] reported for the first time that the portion of the daytime ambulatory blood pressure, which was not already explained by systolic or diastolic clinic blood pressure, could discriminate high-risk from 

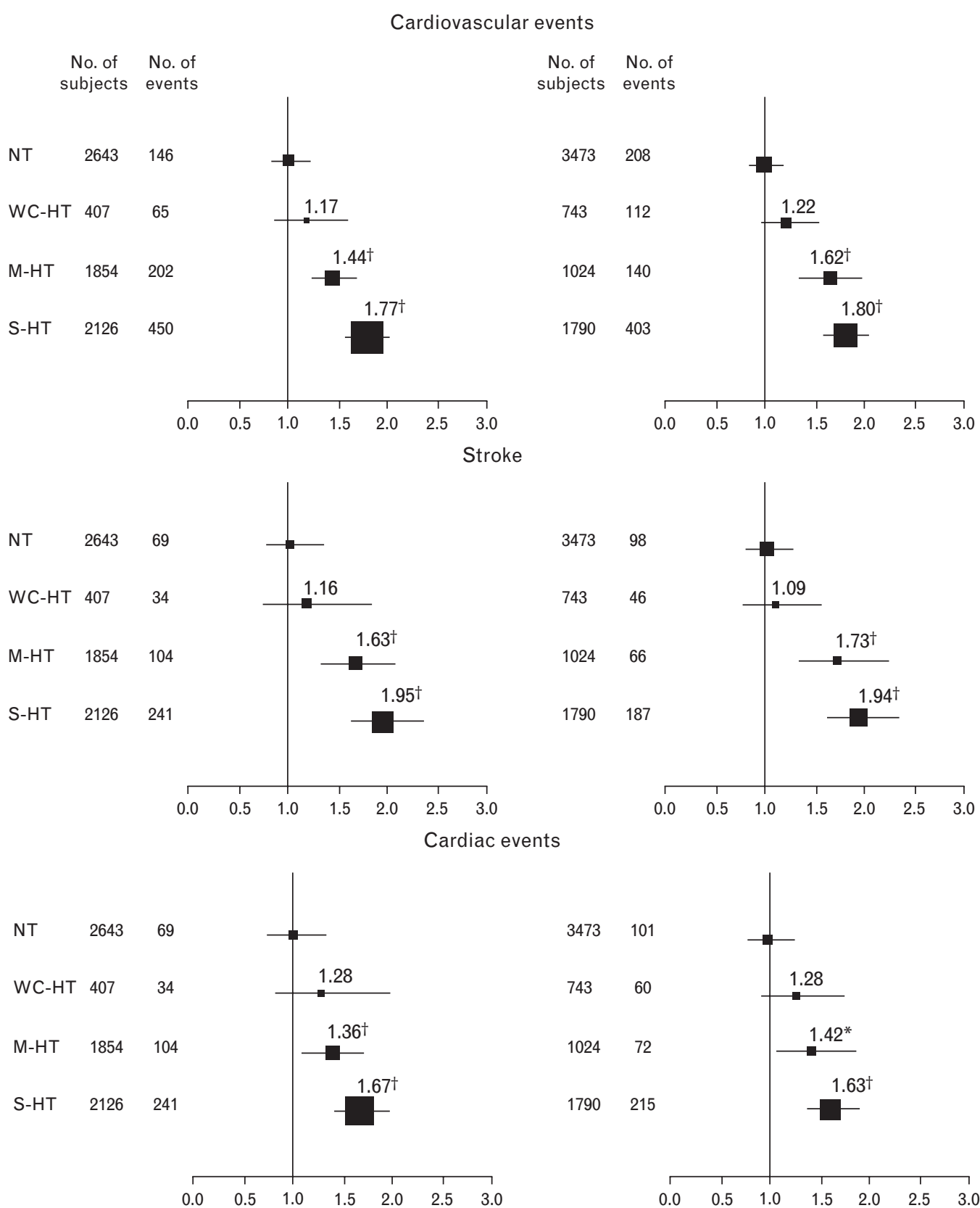

Hazard ratios for cardiovascular events according to the cross-classification of conventional and daytime ambulatory blood pressure. NT, normotension; WC-HT, white-coat hypertension; M-HT, masked hypertension; S-HT, sustained hypertension. NT is the reference group $(* P<0.01$; $\left.{ }^{\dagger} P<0.001\right)$. The analyses were based on (a) lower $(\geq 130 / 80 \mathrm{mmHg})$ or $(\mathrm{b})$ higher $(\geq 135 / 85 \mathrm{mmHg})$ cut-off limits for ambulatory hypertension and were adjusted for cohort, sex, age, body mass index, serum cholesterol, smoking and drinking, history of cardiovascular disease, diabetes mellitus, and antihypertensive drug treatment. Squares are proportional to the number of events per group. Horizontal lines denote the $95 \%$ confidence interval.

low-risk hypertensive patients. These results obtained by life-table analysis from semi-automated recordings in 1076 hypertensive patients were later confirmed by Cox regression in a subgroup of 761 patients, who were all untreated at baseline [38]. Subsequently, several studies replicated Perloff's seminal observations in hypertensive patients [3-7,39-42] or population cohorts [9,11-13]. On balance, these studies confirmed that ambulatory blood pressure monitoring provided better prognostic accuracy than conventional blood pressure 
Table 4 Hazard ratios for cardiovascular event in subgroups with daytime blood pressure threshold set at $135 / 85 \mathrm{mmHg}$

\begin{tabular}{|c|c|c|c|c|c|}
\hline Stratification & At risk $(n)$ & Events $(n)$ & White-coat HT & Masked HT & Sustained HT \\
\hline \multicolumn{6}{|l|}{ Baseline characteristic } \\
\hline Women & 3148 & 211 & $0.90(0.53-1.53)$ & $1.85(1.23-2.77)^{\ddagger}$ & $1.74(1.22-2.49)^{\ddagger}$ \\
\hline Men & 3882 & 652 & $1.37(0.99-1.89)$ & $1.53(1.13-2.07)^{\ddagger}$ & $1.83(1.43-2.33)^{\ddagger}$ \\
\hline$<60$ years & 3555 & 118 & $0.68(0.28-1.67)$ & $1.79(1.16-2.76)^{\ddagger}$ & $2.20(1.48-3.29)^{\ddagger}$ \\
\hline$\geq 60$ years & 3475 & 745 & $1.27(0.95-1.70)$ & $1.57(1.20-2.06)^{\ddagger}$ & $1.74(1.40-2.17)^{\ddagger}$ \\
\hline Untreated & 5510 & 489 & $1.25(0.86-1.82)$ & $1.58(1.17-2.12)^{\ddagger}$ & $1.91(1.48-2.45)^{\ddagger}$ \\
\hline Treated & 1520 & 374 & $1.15(0.76-1.75)$ & $1.69(1.12-2.57)^{\dagger}$ & $1.65(1.19-2.30)^{\ddagger}$ \\
\hline No history of CVD & 6437 & 659 & $1.19(0.91-1.57)$ & $1.72(1.40-2.12)^{\ddagger}$ & $1.90(1.65-2.19)^{\ddagger}$ \\
\hline History of CVD & 593 & 204 & $1.23(0.74-2.05)$ & $1.34(0.79-2.28)$ & $1.55(1.04-2.30)^{*}$ \\
\hline \multicolumn{6}{|l|}{ Excluded cohort } \\
\hline Copenhagen & 4735 & 595 & $1.26(0.91-1.74)$ & $1.64(1.18-2.27)^{\ddagger}$ & $1.87(1.43-2.44)^{\ddagger}$ \\
\hline Noorderkempen & 4755 & 746 & $1.18(0.86-1.63)$ & $1.64(1.26-2.13)^{\ddagger}$ & $1.68(1.34-2.12)^{\ddagger}$ \\
\hline Ohasama & 5711 & 712 & $1.27(0.93-1.74)$ & $1.56(1.18-2.07)^{\ddagger}$ & $1.82(1.45-2.29)^{\ddagger}$ \\
\hline Uppsala & 5896 & 536 & $1.14(0.82-1.58)$ & $1.63(1.24-2.12)^{\ddagger}$ & $1.86(1.47-2.35)^{\ddagger}$ \\
\hline \multicolumn{6}{|c|}{ Incident CABG and PTCA } \\
\hline Included & 7030 & 863 & $1.23(0.93-1.63)$ & $1.67(1.31-2.13)^{\ddagger}$ & $1.83(1.48-2.25)^{\ddagger}$ \\
\hline Excluded & 7030 & 843 & $1.23(0.92-1.63)$ & $1.68(1.31-2.15)^{\ddagger}$ & $1.83(1.49-2.26)^{\ddagger}$ \\
\hline
\end{tabular}

HT, Hypertension; CVD, cardiovascular disease; CABG, coronary artery bypass surgery; PTCA, percutaneous transluminal coronary angioplasty. The hazard ratios (95\% confidence interval) express the risk versus normotension and are adjusted, as appropriate, for cohort, sex, age, body mass index, serum cholesterol, smoking and drinking, history of cardiovascular disease, diabetes mellitus, and antihypertensive drug treatment. Significance of the hazard ratios: ${ }^{*} P<0.05,{ }^{\dagger} P<0.01,{ }^{\ddagger} P<0.001$.

measurement. However, many studies [3-8], although outcome-driven, were difficult to interpret because blood pressure was not analyzed as a continuous variable [3-7], because some studies did not include a normotensive control group $[4,5,7]$, or because investigators did not subdivide the normotensive controls into those with normal or elevated ambulatory blood pressure $[3,6,8]$.

The current literature illustrates that expert opinion over the prognostic significance of white-coat hypertension remains widely divided [3-12]. For example, an early study by Verdecchia et al. [3] included 1187 subjects with essential hypertension and 205 healthy normotensive control subjects, who all underwent baseline off-therapy 24-h ambulatory blood pressure monitoring. In the hypertensive patients, the prevalence of white-coat hypertension, defined as an average daytime blood pressure lower than $131 / 86 \mathrm{mmHg}$ in women and $136 / 87 \mathrm{mmHg}$ in men, was $19.2 \%$. After adjustment for traditional markers of cardiovascular risk, the incidence of morbidity over a mean follow-up of 3.2 years did not differ between the normotensive subjects and the white-coat hypertensive group $(P=0.83)$ [3]. Among 2051 subjects recruited from a general Italian population [12], the PAMELA (Pressione Arteriose Monitorate e Loro Associazione) investigators found a significant sex and age-adjusted increasing trend in the risk of cardiovascular mortality from normotension over white-coat hypertension and masked hypertension, to sustained hypertension. They suggested that the risk associated with white-coat hypertension and masked hypertension is not prognostically innocent [12]. However, the adjusted risk conferred by white-coat and masked hypertension did not significantly differ from that associated with normotension [12]. In the PAMELA publication, the threshold for ambulatory hypertension was a 24-h blood pressure of $125 \mathrm{mmHg}$ systolic or $79 \mathrm{mmHg}$ diastolic [12]. A recently published meta-analysis [10] included three cohorts of hypertensive patients and one population sample. After 6 years of follow-up, patients with white-coat hypertension experienced a substantial increase in the incidence of stroke so that, by the ninth year of follow-up, they had attained the same stroke rate as patients with sustained hypertension [10]. However, over the whole follow-up, the multivariate-adjusted hazard ratio for stroke for white-coat hypertension compared to normotension (1.14; 95\% CI $=0.61-2.16 ; P=0.66)$ was not significant [10]. In our current analyses, the risk of stroke associated with white-coat hypertension versus normotension did not increase with the duration of follow-up.

The counterpart of white-coat hypertension is masked hypertension, a disorder characterized by a normal conventional blood pressure confirmed on repeated clinic visits, and an elevated daytime ambulatory blood pressure [43]. Three studies [9,11,13] defined masked hypertension based on an awake or daytime blood pressure of at least $135 \mathrm{mmHg}$ systolic or $85 \mathrm{mmHg}$ diastolic. Although the adjusted hazard ratio associated with masked hypertension was not significant [11] or not formally compared with that of sustained hypertension $[9,11,13]$, the three reports concluded that masked and sustained hypertension conferred similar cardiovascular risk. Based on an at least ten-fold larger number of composite cardiovascular endpoints, we found that, with proper adjustments applied, the risk of masked hypertension and sustained hypertension was of the same order of magnitude. The only exception was the lower risk of the composite cardiovascular endpoint in masked compared with sustained hypertension (hazard ratio $=1.44$ versus 1.77 ), when we applied levels of $130 \mathrm{mmHg}$ systolic and $80 \mathrm{mmHg}$ diastolic as thresholds for the daytime ambulatory blood pressure. Fewer events and a lack of statistical power probably explain why at the lower 
daytime thresholds the hazard ratios for stroke and cardiac events did not significantly differ between masked and sustained hypertension. In adolescents, masked hypertension is a forerunner of sustained hypertension and is also associated with increased left ventricular mass, and therefore warrants follow-up [44].

In the current meta-analysis, we pre-emptively opted not to combine hypertensive patients and subjects randomly recruited from the general population [14]. We considered that, in hypertensive patients, blood pressurelowering treatment might be a confounder with too large an impact to adjust for [14]. Indeed, in the older patients with isolated systolic hypertension randomized to placebo $(n=393)$ in the Systolic Hypertension in Europe (Syst-Eur) trial [41], the 24-h, daytime ( $1000 \mathrm{~h}$ to $2000 \mathrm{~h}$ ) and night-time ( $0000 \mathrm{~h}$ to $0600 \mathrm{~h}$ ) systolic blood pressures all predicted the incidence of cardiovascular complications, even after further adjustment for conventional blood pressure. By contrast, in the active treatment group $(n=415)$, systolic blood pressure at entry did not significantly predict cardiovascular endpoints, regardless of the technique of blood pressure measurement [41]. In our current meta-analysis, only one-fifth of the subjects were on antihypertensive drug treatment at baseline. The sensitivity analysis in untreated subjects substantiated our overall conclusions and exemplified that antihypertensive drug treatment at baseline was not a major confounder. In addition, the generalizability of population-based results is obviously larger than those emerging from selected cohorts of hypertensive patients. Furthermore, in contrast to other studies [12,39] relating cardiovascular outcomes to conventional and ambulatory blood pressure measurements, we chose to analyze both fatal and nonfatal outcomes. The introduction of stroke units and the wide availability of invasive coronary care and thrombolysis recently reduced the case-fatality rate of most cardiovascular complications of hypertension. Not accounting for nonfatal events therefore limits the generalizability of some previous reports $[12,33,39]$.

Current guidelines for the management of hypertension move away from the concept of blood pressure as an isolated risk factor and increasingly introduce the concept of the management of global cardiovascular risk [45]. From this point of view, our current findings have implications for clinical practice. The prevalence of white-coat hypertension, as evaluated by either ambulatory monitoring $[11,12]$ or blood pressure self-measurement [46,47], varies from $11.5 \%$ [11] to $17.5 \%$ [12] in the general population, and from $13.3 \%$ [46] to $43.0 \%$ [47] among hypertensive patients. Hypertension and associated risk factors are age dependent. Any man normotensive at 50 years has a probability of over $90 \%$ to become hypertensive during the remainder of his lifetime [48]. The aging of populations is a worldwide phenomenon, which is putting increasing demands on limited healthcare resources. Superior risk stratification is a way of objectively informing treatment decisions and rationally distributing medical care. A 6-month clinical trial has already proved that optimizing antihypertensive drug treatment on the basis of ambulatory monitoring is feasible and cost-effective [49]. Our present findings therefore suggest that ambulatory blood pressure monitoring should become routine in the risk stratification of patients with hypertension.

Our study must be interpreted within the context of its potential limitations. First, our present analysis rested only on four population-based cohorts and might not be representative for non-European or non-Japanese subjects. Second, anthropometric characteristics differed between cohorts. Third, most participants had their conventional blood pressure measured while seated at an examination centre. By contrast, the conventional blood pressure was measured in the supine position in Uppsala [13] and at home in Noorderkempen [18,34]. Due to regression to the mean, the most recent consensus [2] states that a diagnosis of white-coat hypertension requires measurement of a conventional blood pressure of $140 \mathrm{mmHg}$ systolic or $90 \mathrm{mmHg}$ diastolic or higher on at least three occasions. Furthermore, ambulatory blood pressure monitoring was not standardized in terms of device type and intervals between successive readings. On the other hand, using a single SAS macro ensured that daytime was always defined in the same fashion, using short fixed clock-time intervals [50], and that the timeweighted means were calculated identically across cohorts. The inclusion of cases of surgical and percutaneous coronary revascularization among the coronary and cardiovascular events might have limited the generalizability of the results because these procedures are subject to considerable regional variation in practice. However, our analyses only included 26 such cases and their exclusion confirmed our results for coronary heart disease, as well as all cardiovascular events. Finally, we did not adjust for antihypertensive drug treatment as a time-dependent covariate. However, the proportion of our patients on antihypertensive treatment at baseline was only $21.6 \%$. During the course of follow-up, the proportion of treated patients, giving the poor rates of treatment in the general population [51] and the poor persistence of treatment in some clinical studies [52], must have been considerably lower than in cohorts of referred hypertensive patients, followed up at specialized hypertension centres [3-7,40] or started on antihypertensive treatment at enrolment $[4,7,40]$.

In conclusion, ambulatory monitoring is superior to conventional blood pressure measurement in the prediction of cardiovascular events. Cardiovascular risk gradually increases from normotension over white-coat hypertension and masked hypertension to sustained hypertension. 
Risk charts combining ambulatory and conventional blood pressure measurements along with established other risk factors are under construction and might improve risk stratification and the targeted administration of medical care.

\section{IDACO centres and investigators}

Belgium (Noorderkempen): R. Fagard, T. Kuznetsova, T. Richart, J. A. Staessen, L. Thijs; China (JingNing): Y. Li, J. G. Wang; the Czech Republic (Pilsen): J. Filipovský, J. Seidlerová, M. Tichá; Denmark (Copenhagen): T. W. Hansen, H. Ibsen, J. Jeppesen, S. Rasmussen, C. Torp-Pedersen; Italy (Padua): E. Casiglia, A. Pizzioli, V. Tikhonoff; Ireland (Dublin): Eamon Dolan, Eoin O'Brien; Japan (Ohasama): K. Asayama, J. Hashimoto, H. Hoshi, Y. Imai, R. Inoue, M. Kikuya, H. Metoki, T. Obara, T. Ohkubo, H. Satoh, K. Totsune; Poland (Cracow): A. Adamkiewicz-Piejko, M. Cwynar, J. Gąsowski, T. Grodzicki, K. Kawecka-Jaszcz, W. Lubaszewski, A. Olszanecka, K. Stolarz, B. Wizner, W. Wojciechowska, J. Zyczkowska; the Russian Federation (Novosibirsk): T. Kuznetsova, S. Malyutina, Y. Nikitin, E. Pello, G. Simonova, M. Voevoda; Sweden (Uppsala): B. Andrén, L. Berglund, K. Björklund-Bodegård, L. Lind, B. Zethelius; Uruguay (Montevideo): M. Bianchi, V. Moreira, E. Sandoya, C. Schettini, E. Schwedt, H. Senra.

\section{Acknowledgements}

The authors gratefully acknowledge the expert assistance of Sandra Covens, Katrien Staessen, and Renilde Wolfs (Leuven, Belgium).

The European Union (grants IC15-CT98-0329-EPOGH and LSHM-CT-2006-037093), the Fonds voor Wetenschappelijk Onderzoek Vlaanderen, Ministry of the Flemish Community, Brussels, Belgium (grants G.0424.03 and G.0575.06), and the Katholieke Universiteit Leuven, Belgium (grants OT/99/28, OT/00/25 and OT/05/49) gave support to the Studies Coordinating Centre. J.A.S. is holder of the Pfizer Chair for Hypertension and Cardiovascular Research (http://www.kuleuven.be/mecenaat/leerstoelen/ overzicht.htm). The Danish Heart Foundation (grant 01-2-9-9A-22914), the Beckett Fonden, and the Lundbeck Fonden supported the studies in Copenhagen. The Ministry of Education, Culture, Sports, Sciences and Technology (grants 15790293, 17790381, 18390192 and 18590587) and the Ministry of Health, Labor and Welfare (Health Science Research Grants and Medical Technology Evaluation Research Grants), the Japanese Society for the Promotion of Science (grants 16.54041 and 18.54042), the Japan Atherosclerosis Prevention Fund, the Uehara Memorial Foundation, and the Takeda Medical Research Foundation supported research in Japan.

There are no conflicts of interest.

\section{References}

1 Chobanian AV, Bakris GL, Black HR, Cushman WC, Green LA, Izzo JL Jr, et al. Seventh report of the Joint National Committee on Prevention, Detection and Evaluation, and Treatment of High Blood Pressure. Hypertension 2003; 42:1206-1252.

2 O'Brien E, Asmar R, Beilin L, Imai Y, Mancia G, Mengden T, et al. Practice guidelines of the European Society of Hypertension for clinic, ambulatory and self blood pressure measurement. J Hypertens 2005; 23:697-701.

3 Verdecchia P, Porcellati C, Schillaci G, Borgioni C, Ciucci A, Battistelli M, et al. Ambulatory blood pressure. An independent predictor of prognosis in essential hypertension. Hypertension 1994; 24:793-801.

4 Khattar RS, Senior R, Lahiri A. Cardiovascular outcome in white-coat versus sustained mild hypertension. A 10-year follow-up study. Circulation 1998; 98:1892-1897.

5 Fagard RH, Staessen JA, Thijs L, Gasowski J, Bulpitt CJ, Clement D, et al. Response to antihypertensive therapy in older patients with sustained and nonsustained systolic hypertension. Circulation 2000; 102:1139-1144.

6 Kario K, Shimada K, Schwartz JE, Matsuo T, Hoshide S, Pickering TG. Silent and clinically overt stroke in older Japanese subjects with white-coat and sustained hypertension. J Am Coll Cardiol 2001; 38:238-245.

7 Celis H, Staessen JA, Thijs L, Buntinx F, De Buyzere M, Den Hond E, et al. Cardiovascular risk in white-coat and sustained hypertensive patients. Blood Press 2002; 11:352-356.

8 Gustavsen PH, Hoegholm A, Bang LE, Kristensen KS. White coat hypertension is a cardiovascular risk factor: a 10-year follow-up study. J Hum Hypertens 2003; 17:811-817.

9 Ohkubo T, Kikuya K, Metoki H, Asayama K, Obara T, Hashimoto J, et al. Prognosis of 'masked" hypertension and 'white-coat' hypertension detected by 24-h ambulatory blood pressure monitoring. 10-year follow-up from the Ohasama study. J Am Coll Cardiol 2005; 46:508-515.

10 Verdecchia P, Reboldi GP, Angeli F, Schillaci G, Schwartz JE, Pickering TG, et al. Short- and long-term incidence of stroke in white-coat hypertension. Hypertension 2005; 45:203-208.

11 Hansen TW, Jeppesen J, Rasmussen S, Ibsen H, Torp-Pedersen C. Ambulatory blood pressure and risk of cardiovascular disease: a population based study. Am J Hypertens 2006; 19:243-259.

12 Mancia G, Facchetti R, Bombelli M, Grassi G, Sega R. Long-term risk of mortality associated with selective and combined elevation in office, home, and ambulatory blood pressure. Hypertension 2006; 47:846-853.

13 Björklund K, Lind L, Zethelius B, Andrén B, Lithell H. Isolated ambulatory hypertension predicts cardiovascular morbidity in elderly men. Circulation 2003; 107:1297-1302.

14 Thijs L, Hansen TW, Kikuya M, Björklund-Bodegård K, Li Y, Dolan E, et al. The International Database of Ambulatory blood pressure in relation to Cardiovascular Outcome (IDACO): protocol and reseacrh perspectives. Blood Press Monit 2007 (in press).

15 Kikuya M, Hansen TW, Thijs L, Björklund-Bodegård K, Kuznetsova T, Ohkubo $\mathrm{T}$, et al. Diagnostic thresholds for ambulatory blood pressure monitoring based on 10-year cardiovascular risk. Circulation 2007 (in press).

16 Ohkubo T, Imai Y, Tsuji I, Nagai K, Ito S, Satoh H, et al. Reference values for 24-h ambulatory blood pressure monitoring based on a prognositic criterion. The Ohasama Study. Hypertension 1998; 32:255-259.

17 Kuznetsova T, Malyutina S, Pello E, Thijs L, Nikitin Y, Staessen JA. Ambulatory blood pressure of adults in Novosibirsk, Russia: interim report on a population study. Blood Press Monit 2000; 5:291-296.

18 Staessen JA, Bieniaszewski L, O'Brien ET, Imai Y, Fagard R. An epidemiological approach to ambulatory blood pressure monitoring: the Belgian population study. Blood Press Monit 1996; 1:13-26.

19 Li Y, Wang JG, Gao HF, Nawrot T, Wang GL, Qian YS, et al. Are published characteristics of the ambulatory blood pressure generalizable to rural Chinese? The JingNing population study. Blood Press Monit 2005; 10:125-134.

20 O'Brien E, Murphy J, Tyndall A, Atkins N, Mee F, McCarthy G, et al. Twentyfour-hour ambulatory blood pressure in men and women aged 17 to 80 years: the Allied Irish Bank Study. J Hypertens 1991; 9:355-360.

21 Schettini C, Bianchi M, Nieto F, Sandoya E, Senra H, Hypertension Working Group. Ambulatory blood pressure. Normality and comparison with other measurements. Hypertension 1999; 34 (part 2):818-825.

22 Casiglia E, Basso G, Guglielmi F, Martini B, Mazza A, Tikhonoff V, et al. German origin clusters for high cardiovascular risk in an Italian enclave. Int Heart J 2005; 46:489-500.

23 Shiburi CP, Staessen JA, Maseko M, Wojciechowska W, Thijs L, Van Bortel LM, et al. Reference values for SphygmoCor measurements in South Africans of African ancestry. Am J Hypertens 2006; 19:40-46.

24 Imai $Y$, Nagai K, Sakuma M, Sakuma H, Nakatsuka $\mathrm{H}$, Satoh $\mathrm{H}$, et al. Ambulatory blood pressure of adults in Ohasama, Japan. Hypertension 1993; 22:900-912. 
25 Taylor R, Chidley K, Goodwin J, Broeders M, Kirby B. Accutracker II (version 30/23) ambulatory blood pressure monitor: clinical validation using the British Hypertensin Society and Association for the Advancement of Medical Instrumentation standards. J Hypertens 1993; 11:1275-1282.

26 O'Brien E, Mee F, Atkins N, O'Malley K. Evaluation of the SpaceLabs 90202 noninvasive ambulatory recorder according to the AAMI Standard and BHS criteria. J Hum Hypertens 1991; 5:223-226.

27 O'Brien E, Mee F, Atkins N, O'Malley K. Accuracy of the SpaceLabs 90207 determined by the British Hypertension Society Protocol. J Hypertens 1991; 9:573-574.

28 Imai Y, Sasaki S, Minami N, Munakata M, Hashimoto J, Sakuma H, et al. The accuracy and performance of the A\&D TM 2421, a new ambulatory blood pressure monitoring device based on the cuff-oscillometric method and the Korotkoff sound technique. Am J Hypertens 1992; 5:719-726.

29 Imai Y, Abe K, Sasaki S, Minami N, Munakata M, Sekino H, et al. Determination of clinical accuracy and nocturnal blood pressure pattern by new portable device for monitoring indirect ambulatory blood pressure. Am J Hypertens 1990; 3:293-301.

30 Imai Y, Nihei M, Abe K, Sasaki S, Minami N, Munakata M, et al. A finger volume-oscillometric device for monitoring ambulatory blood pressure: laboratory and clinical evaluation. Clin Exp Hypertens 1987; 9:20012025.

31 Verdecchia P, Schillaci G, Boldrini F, Zampi I, Porcellati C. Variability between current definitions of 'normal' ambulatory blood pressure. Implications in the assessment of white coat hypertension. Hypertension 1992; 20:555-562.

32 Expert Committee on the Diagnosis and Classification of Diabetes Mellitus. Report of the expert committee on the diagnosis and classification of diabetes mellitus. Diabetes Care 2003; 26 (Suppl 1): S5-S20.

33 Kikuya M, Ohkubo T, Asayama K, Metoki H, Obara T, Saito S. Ambulatory blood pressure and 10-years risk of cardiovascular and noncardiovascular mortality the Ohasama study. Hypertension 2005; 45:240-245.

34 Li Y, Thijs L, Kuznetsova T, Zagato L, Struijker-Boudier H, Bianchi G, et al. Cardiovascular risk in relation to $\alpha$-addicin Gly460Trp polymorphism and systolic pressure. A prospective population study. Hypertension 2005; 46:527-532.

35 Darne B, Girerd X, Safar M, Cambien F, Guize L. Pulsatile versus steady component of blood pressure: a cross-sectional analysis and a prospective analysis on cardiovascular mortality. Hypertension 1989; 13:392-400.

36 Easton DF, Peto J, Babiker AGAG. Floating absolute risk: an alternative to relative risk in survival and case-control analysis avoiding an arbitrary reference group. Stat Med 1991; 10:1025-1035.

37 Perloff D, Sokolow M, Cowan R. The prognostic value of ambulatory blood pressures. JAMA 1983; 249:2792-2798.

38 Perloff D, Sokolow M, Cowan RM, Juster RP. Prognostic value of ambulatory blood pressure measurements: further analyses. J Hypertens 1989; 7 (Suppl 3):S3-S10.

39 Dolan E, Stanton A, Thijs L, Hinedi K, Atkins N, McClory S, et al. Superiority of ambulatory over clinic blood pressure measurement in predicting mortality. The Dublin Outcome Study. Hypertension 2005; 46:156-161.

40 Clement DL, De Buyzere ML, De Bacquer DA, de Leeuw PW, Duprez DA, Fagard $\mathrm{RH}$, et al. Prognostic value of ambulatory blood-pressure recordings in patients with treated hypertension. N Engl J Med 2003; 348:2407-2415.

41 Staessen JA, Thijs L, Fagard R, O'Brien ET, Clement D, de Leeuw PW, et al. Predicting cardiovascular risk using conventional vs ambulatory blood pressure in older patients with systolic hypertension. JAMA 1999; 282:539-546.

42 Redón J, Campos C, Narciso ML, Rodicio JL, Pascual JM, Ruilope LM. Prognostic value of ambulatory blood pressure monitoring in refractory hypertension. A prospective study. Hypertension 1998; 31:712-718.

43 Pickering TG, Davidson K, Gerin W, Schwartz JE. Masked hypertension. Hypertension 2002; 40:795-796.

44 Lurbe E, Torro L, Alvarez V, Nawrot T, Paya R, Redón J, et al. Prevalence, persistence, and clinical significance of masked hypertension in youth. Hypertension 2005; 45:493-498.

45 Staessen JA, O'Brien E. Will generic guidelines reduce the proliferation of directives? Heart 2007 (in press).

46 Bobrie G, Chatellier G, Genès N, Clerson P, Vaur L, Vaïsse B, et al. Cardiovascular prognosis of 'masked hypertension' detected by blood pressure self-measurement in elderly treated hypertensive patients. JAMA 2004; 291:1342-1349.

47 Helvaci MR, Seyhanli M. What a high prevalence of whie coat hypertension in society!. Intern Med 2006; 45:671-674.

48 Vasan RS, Beiser A, Larson MG, Kannel WB, D'Agostino RB, Levy D. Residual lifetime risk of developing hypertension in middle-aged women and men. The Framingham Heart Study. JAMA 2002; 287:10031010.
49 Staessen JA, Byttebier G, Buntinx F, Celis H, O'Brien ET, Fagard R, et al. Antihypertensive treatment based on conventional or ambulatory blood pressure measurement. A randomized controlled trial. JAMA 1997; 278:1065-1072.

50 Fagard R, Brguljan J, Thijs L, Staessen J. Prediction of the actual awake and asleep blood pressures by various methods of $24 \mathrm{~h}$ pressure analysis. J Hypertens 1996; 14:557-563.

51 Weinehall L, Öhgren B, Persson M, Stegmayr B, Boman K, Hallmans G, et al. High remaining risk in poorly treated hypertension: the 'rule of halves' still exist. J Hypertens 2002; 20:2081-2088.

52 Chapman RH, Benner JS, Petrilla AA, Tierce JC, Collins SR, Battleman DS, et al. Predictors of adherence with antihypertensive and lipid-lowering therapy. Arch Intern Med 2005; 165:1147-1152. 